\title{
Influence of the catalyst acid/base properties on the catalytic ethanol dehydration under steady state and dynamic conditions. In situ surface and gas-phase analysis
}

\author{
Serge Golay, Lioubov Kiwi-Minsker, Ralf Doepper, Albert Renken* \\ Departmento de Chimie, Swiss Federal Institute of Technology Lausanne (EPFL), Institute de Genie Chimique, CH-1015 Lausanne, Switzerland
}

\begin{abstract}
The influence of the acid/base properties of $\mathrm{Mg}^{2+}$-modified aluminas on the steady-state and transient behaviour of the ethanol to ethene dehydration has been investigated by simultaneous gas phase and in-situ surface analysis. The steady-state ethanol conversion and the ethene selectivity decrease when the catalyst basicity, i.e., the magnesium concentration, increases. The ethene transient behaviour is characterised by a stop-effect phenomenon, which is a drastic increase of the reaction rate measured for a step-wise decrease in the inlet concentration of ethanol. The relative augmentation of the ethene concentration under dynamic conditions is maximal for the catalyst with a $\mathrm{Mg}^{2+} / \mathrm{Al}^{3+}$ atomic ratio of $2.5 \%$. Compared to stationary experiments, transients are much more sensitive to modifications of the catalyst acid/base properties.

The experiments were described by a model considering the existence of acid and basic sites on the catalyst surface. The magnesium concentration influences the kinetic parameters, whereas the site concentrations do not show any significant variation. (C) 1999 Elsevier Science Ltd. All rights reserved.
\end{abstract}

Keywords: Acid/base properties; Alumina; Ethanol dehydration; FT-IR; Modelling; Transient behaviour

\section{Introduction}

The ethanol dehydration to ethene on $\gamma$-alumina presents a stop-effect behaviour, i.e., a drastic increase of the reaction rate when the feed concentration of the reactant is switched to zero, with a total flow rate kept constant (Koubek et al., 1980a, b; Moravek and Kraus, 1984). In previous studies (Golay et al., 1997, 1998) this reaction was investigated by simultaneous measurements of the gas phase composition by gas chromatography and of the concentration of adsorbed species on the catalyst surface by in situ infrared spectroscopy. The results were described by model A (Eqs. (1)-(4)) which considers the existence of two types of active sites, $S_{1}$ and $S_{2}$, corresponding to acid and basic sites, respectively. The model assumes a strong ethanol adsorption on the acid sites and

\footnotetext{
* Corresponding author. Tel.: +41-21-693 3181; fax: +41-2169331 90; e-mail: albert.renken@epfl.ch.
}

a week one on the basic sites. For the formation of ethene a simultaneous adsorption on both sites $S_{1}$ and $S_{2}$ is necessary. As either the formation or the decomposition of the intermediate complex is rate limiting, the consecutive reaction scheme (Eqs. (10) and (11)) can be simplified to a one step reaction (Eq. (3)). This surface reaction is responsible for the stop-effect: at steady state the reaction rate is low, due to the low concentration of free basic sites. It increases immediately after the stop, due to the instantaneous desorption of the inhibiting species $\mathrm{AS}_{2}$ and liberation of basic sites $\left(\mathrm{S}_{2}\right)$. Diethylether formation, which does not present a stop-effect behaviour, is described for simplicity by a quasi-homogeneous reaction term (Eq. (4)):

\section{Model $A$}

$$
\mathrm{A}+\mathrm{S}_{1} \stackrel{r_{1}}{\rightarrow} \mathrm{AS}_{1}
$$

$$
r_{1}=k_{1} Z_{1} C_{A}\left(1-\theta_{1}\right)
$$

$\mathrm{A}+\mathrm{S}_{2} \stackrel{K_{2}}{\leftrightarrow} \mathrm{AS}_{2}$

$$
\theta_{2}=\frac{K_{2} C_{A}}{1+K_{2} C_{A}},
$$


$\mathrm{AS}_{1}+\mathrm{S}_{2} \stackrel{r_{3}}{\rightarrow} \mathrm{E}+\mathrm{W}+\mathrm{S}_{1}+\mathrm{S}_{2} \quad r_{3}=k_{3} Z_{1} Z_{2} \theta_{1}\left(1-\theta_{2}\right)$,

$2 \mathrm{~A} \stackrel{k_{D}}{\rightarrow} \mathrm{D}+\mathrm{W}$

$$
r_{D}=k_{D} C_{A},
$$

with

$\theta_{1}=\frac{C_{A S_{1}}}{C_{A S_{1}}+C_{S_{1}}}=\frac{C_{A S_{1}}}{Z_{1}}$, and $\theta_{2}=\frac{C_{A S_{2}}}{C_{A S_{2}}+C_{S_{2}}}=\frac{C_{A S_{2}}}{Z_{2}}$

The adsorbed intermediates $\mathrm{AS}_{1}, \mathrm{AS}_{2}$ were identified as ethoxide-like species. Their similar structures produce similar infrared spectra, with no characteristic band for either $\mathrm{AS}_{1}$ or $\mathrm{AS}_{2}$. Therefore, the individual concentrations of the supposed species cannot be determined. Their total concentration is proportional to the calculated height of the $2970 \mathrm{~cm}^{-1}$ absorption band, with a baseline correction between 3100 and $2600 \mathrm{~cm}^{-1}$.

The surface acid/base properties of the catalyst can be modified by incorporating $\mathrm{Mg}^{2+}$ into $\gamma$-alumina, whereas the surface and bulk structures remain similar (KiwiMinsker et al., 1996, 1997). The magnesium cations diffuse into the alumina lattice, leading to the formation of the non-stochiometric spinel $\mathrm{MgAl}_{2} \mathrm{O}_{4}$, with a constant unit cell parameter $a$ of $0.7907 \mathrm{~nm}$.

The aim of the present work is to study the influence of the acid/base properties on the steady-state and transient behaviour of the ethanol dehydration reaction. The stop-effect has been investigated on $\mathrm{Mg}^{2+}$-modified $\gamma$-alumina catalysts, with $\mathrm{Mg}^{2+} / \mathrm{Al}^{3+}$ atomic ratio of 0 , $0.05,0.5,2.5,5.0$, and $7.5 \%$.

\section{Experimental}

The experimental set-up and catalysts preparation have been previously described in detail (Golay et al., 1997; Kiwi-Minsker et al., 1996). The experimental lay-out consisted of two feed sections converging to a four-way valve, a fixed-bed tubular reactor, an infrared transmission cell and a gas chromatograph. The fixedbed reactor was placed just before the infrared cell. Residence time distribution experiments showed that the fixed-bed reactor can be described by a tanks-in-series model, using 9 tanks for the catalyst compartment. The infrared cell behaves like an ideal continuous stirred tank reactor. The carrier gas was argon (>99.99\%, Carbagas, Lausanne, Switzerland) and the ethanol (>99.8\%, No. 02860, Fluka Chemie AG, Buchs, Switzerland) feed was provided by a temperature-controlled bubble column fed by argon. The catalysts were prepared by wet capillary impregnation with aqueous solution of magnesium nitrates. A detailed description of the preparation method is given by Porchet (1996).
The experiments were carried out at temperatures of 180,200 and $220^{\circ} \mathrm{C}$, a pressure of $140 \mathrm{kPa}$, a total flow rate of $200 \mathrm{ml}(\mathrm{NTP}) / \mathrm{min}$, and an initial ethanol concentration of $0.26 \mathrm{~mol} / \mathrm{m}^{3}$. The catalyst mass in the fixed-bed reactor was $495 \mathrm{mg}$, whereas that of the infrared wafers was about $25 \mathrm{mg}$. The transient experiments were carried out in the following manner: $108 \mathrm{~min}$ ethanol/830 $\mathrm{min}$ argon. Prior to the transient measurements, the catalysts were first activated at $415^{\circ} \mathrm{C}$ under inert gas during $4 \mathrm{~h}$ and then exposed to the reaction conditions for $15 \mathrm{~h}$. This procedure allowed to achieve the steady state of the surface since a slow deactivation was observed during the first hours of reaction.

\section{Results and discussion}

\subsection{Steady-state behaviour}

The ethanol conversion and ethene selectivity were observed to decrease with the increase of $\mathrm{Mg}^{2+}$ content added to $\gamma-\mathrm{Al}_{2} \mathrm{O}_{3}$ (Fig. 1). Under steady-state conditions the conversion decreases rapidly by adding $0.5 \% \mathrm{Mg}^{2+}$ from $60 \%$ to about $40 \%$ and tends to a plateau for higher magnesium concentrations.

The infrared spectra of the $\mathrm{Mg}^{2+}$-modified aluminas (Fig. 2) exhibit similar infrared bands than those of the pure $\gamma$-alumina (Golay et al., 1997, 1998). Porchet (1996) has reported a shift of the $\mathrm{C}-\mathrm{H}$ stretching vibrations to lower wave numbers for the adsorption of methanol on $\mathrm{Mg}^{2+}$-modified alumina, with magnesium content up to $30 \%$. No significant shift can be observed on the spectra presented in Fig. 2, due to the relatively low magnesium concentration in the catalysts used.

The incorporation of $\mathrm{Mg}^{2+}$ into the $\gamma$-alumina lattice leads to an increase of the strength of the basic sites and a simultaneous decrease of the acid sites (Kiwi-Minsker et al., 1996, 1997).

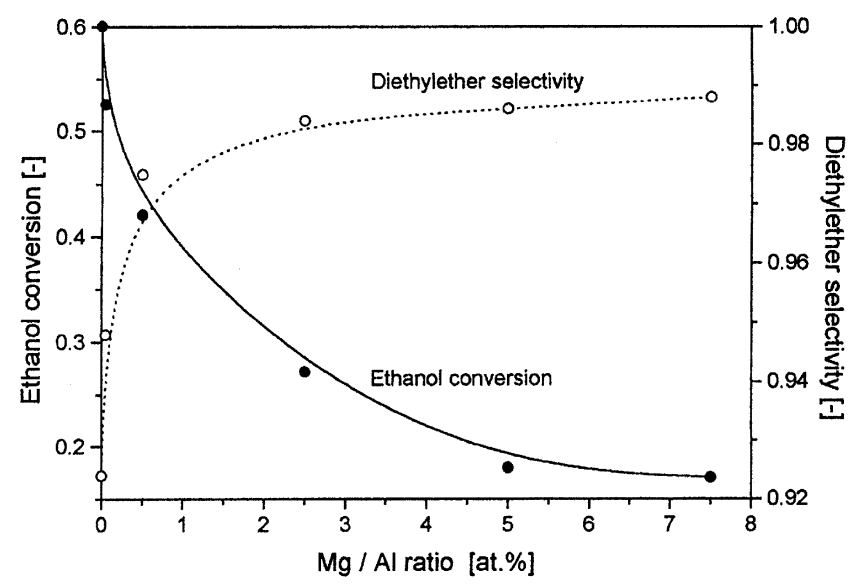

Fig. 1. Influence of the $\mathrm{Mg} / \mathrm{Al}$ atomic ratio on the steady-state conversion and the diethylether selectivity at $200^{\circ} \mathrm{C}$. 


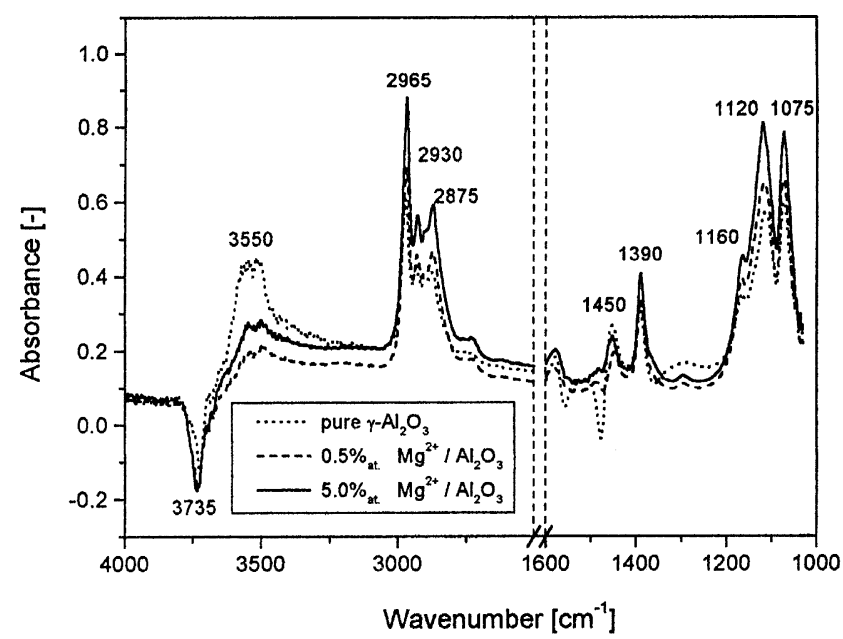

Fig. 2. Spectra of the $0,0.5$ and 5.0 at $\%$. $\mathrm{Mg}^{2+}$-modified catalysts under steady-state conditions at $200^{\circ} \mathrm{C}$.

The decrease of the surface acidity results in a strengthen of the $\mathrm{C}_{2} \mathrm{H}_{5}-\mathrm{O}$ bond leading to preferred ether formation.

\subsection{Transient behaviour}

The ethene transients measured at $200^{\circ} \mathrm{C}$ are shown in Fig. 3a. It can be seen that an increase of the magnesium concentration leads to a slowing down of the stop-effect kinetics: after the feed is switched to inert gas, the ethene concentration reaches the transient maximum within less than $1 \mathrm{~min}$ for the pure alumina catalyst, whereas this process takes about $100 \mathrm{~min}$ with the $5 \% \mathrm{Mg}^{2+}$-modified $\gamma$-alumina. The relative increase of the maximal ethene concentration under transient conditions increases with the surface basicity. It passes through a maximum for the $2.5 \% \mathrm{Mg}^{2+}$ catalyst and then decreases for higher magnesium concentrations.

At the end of the transients a second rate enhancement is observed on the pure and $0.05 \% \mathrm{Mg}^{2+}$-modified aluminas. As this effect is not described by model A, only the first part of the transients will be considered for the modelling.

The decreasing rate within the transient period is also observed for the desorption behaviour of the adsorbed surface species (Fig. 3b). The infrared signal decrease after the stop becomes slower with the increase of the magnesium content in the catalyst. The relative decrease observed immediately after the stop of the ethanol feed, which is supposed to be due to the desorption of the inhibiting species, $\mathrm{AS}_{2}$, decreases with increased surface basicity.

\subsection{Modelling}

Model A (Eqs. (1)-(4)) was used to describe the transient behaviour after the ethanol feed stop.
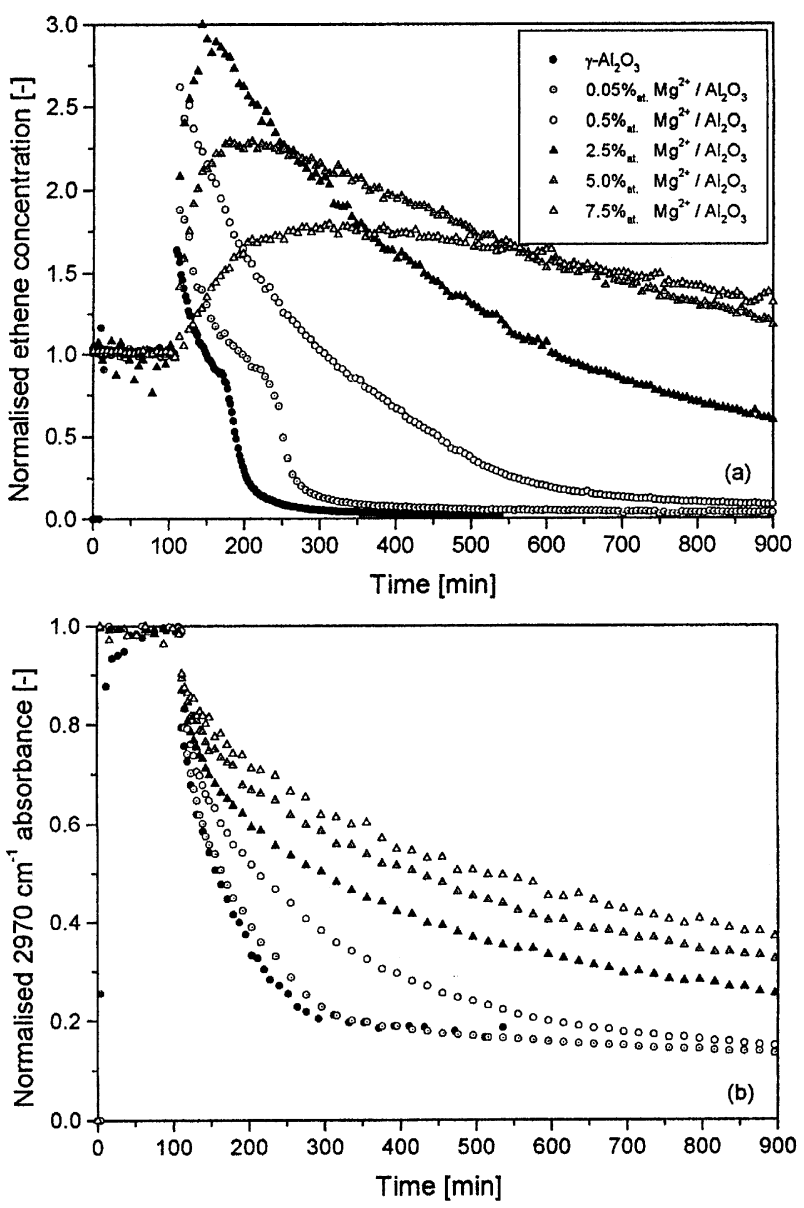

Fig. 3. Influence of the magnesium content on the transients responses of (a) the ethene and (b) the surface at $200^{\circ} \mathrm{C}$.

The infrared signal is supposed to be proportional to the amount of adsorbed species on $\mathrm{S}_{1}$ and $\mathrm{S}_{2}$ as well as the amount of a spectator species, which does not participate to the ethene formation and which accumulates slowly on the catalyst surface (Golay et al., 1998). The signal is calculated by Eq. (6):

$\mathrm{IR}=h_{\text {spectator }}+\alpha m_{\text {cat,cell }} Z_{1}\left(\theta_{1}+\theta_{2} \varphi\right)$

with $\varphi=\frac{Z_{2}}{Z_{1}}$.

The differential equations of the mass balance for the gas phase and the surface species were solved simultaneously as a function of time and axial position in the reactor, using the Gear variable step integration algorithm (Simusolv, 1990). The simulations were started with the ethanol feeding $15 \mathrm{~h}$ before the first transient experiment.

The values of $Z_{1}$ and $\varphi$ do not show any significant variation with the magnesium content, and they were kept constant during the simulations. This is in agreement with the hypothesis that the introduction of magnesium does not modify the total amount of acid and basic sites. The values determined for pure alumina (Golay, 
1998), $Z_{1}=0.69 \mathrm{~mol} / \mathrm{kg}_{\text {cat }}$ and $\varphi=0.84$, were used. The formation of the spectator species also occurs on the modified catalysts, as it can be seen in Fig. 3b. The offset value, $h_{\text {spectator }}$, is identical for the pure alumina, the 0.05 and the $0.5 \%$ catalysts. It is not possible to determine this value for the higher magnesium concentrations, since ethene is still formed at the end of the transient measurements. Therefore, the average values of $0.11,0.07$ and 0.06 derived form the transients measured on pure alumina (Golay, 1998) were employed for the reaction temperatures of 180,200 and $220^{\circ} \mathrm{C}$, respectively. The parameters $k_{1}, K_{2}, k_{3}, k_{D}$ and $\alpha$ were simultaneously optimised to describe the ethene transients.

The optimisations were carried out using the Nelder-Mead search algorithm and the likelihood function as the objective function (Simusolv, 1990).

A good agreement is achieved for the gas phase and the surface transients, for aluminas with a low magnesium concentration, i.e., 0.05 and $0.5 \%$. However, for higher magnesium contents the model fails to describe the transients, as it can be seen in Fig. 4. It predicts a much faster increase of the ethene concentration in the gas phase than experimentally observed. The calculated desorption rate
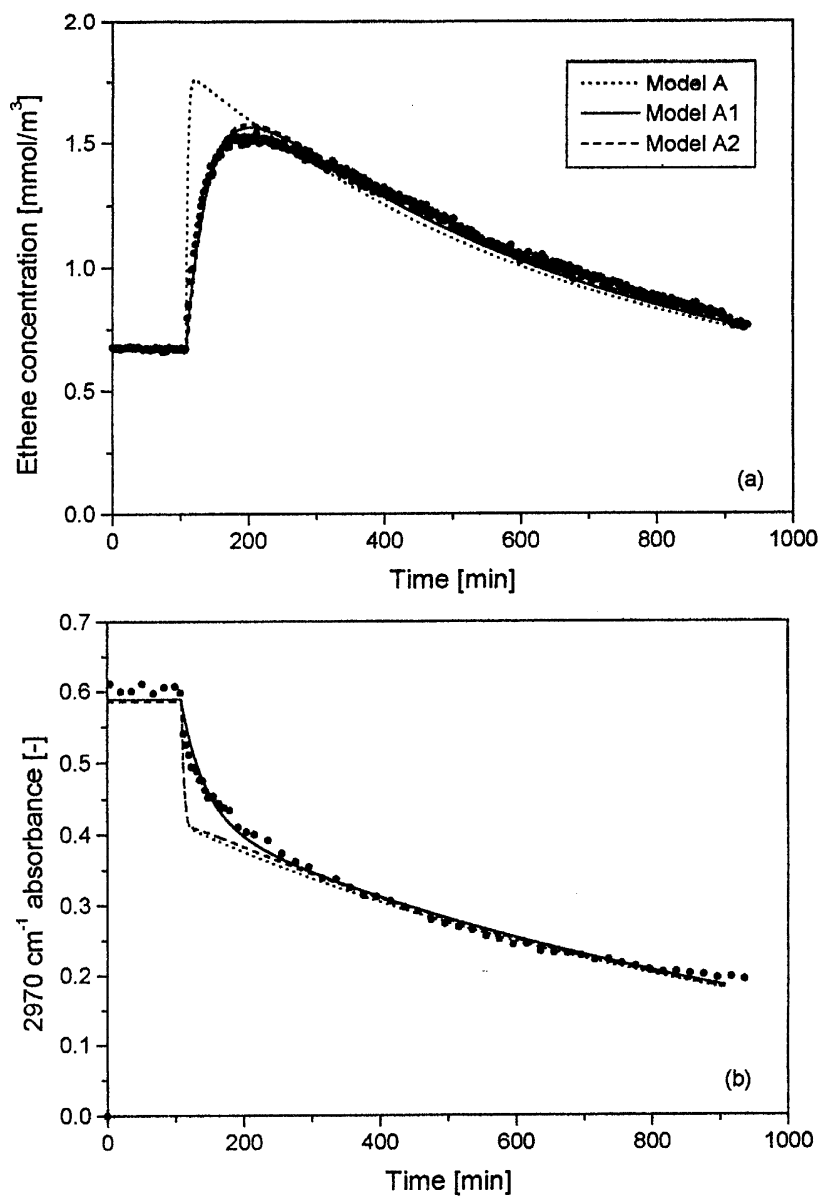

Fig. 4. Modelling result for the $5.0 \% \mathrm{Mg}^{2+}$ catalyst, for (a) ethene and (b) surface at $200^{\circ} \mathrm{C}$. of the surface species immediately after the ethanol feed stop is also overestimated.

To describe the observed slower rates within the transient periods, two models based on model A were tested.

In model A1 it is assumed that an instantaneous equilibrium between gas phase concentration and surface concentration on $\mathrm{S}_{2}$ sites is no longer valid and a finite adsorption and desorption rate is considered. In model A2 it is supposed that the formation of the intermediate complex with a basic site $\left(\mathrm{S}_{2} \mathrm{AS}_{1}\right)$ becomes rate influencing (Eqs. (10) and (11)).

\section{Model A1:}

$\mathrm{A}+\mathrm{S}_{2} \stackrel{k_{2}}{\rightarrow} \mathrm{AS}_{2}$
$\mathrm{AS}_{2} \stackrel{k_{-2}}{\rightarrow} \mathrm{A}+\mathrm{S}_{2}$$\quad\left\{\begin{array}{l}r_{2}=k_{2} Z_{2} C_{A}\left(1-\theta_{2}\right) \\ r_{-2}=k_{-2} Z_{2} \theta_{2}\end{array}\right.$

\section{Model A2:}

$$
\begin{gathered}
\mathrm{AS}_{1}+\mathrm{S}_{2} \stackrel{k_{3 \mathrm{a}}}{\rightarrow} \mathrm{S}_{2} \mathrm{AS}_{1} \stackrel{k_{3 \mathrm{~b}}}{\rightarrow} \mathrm{E}+\mathrm{W}+\mathrm{S}_{1}+\mathrm{S}_{2} \\
\left\{\begin{array}{l}
r_{3 \mathrm{a}}=k_{3 \mathrm{a}} Z_{1} Z_{2} \theta_{1}\left(1-\theta_{2}-\frac{1}{\varphi} \theta_{1}^{\circ}\right) \\
r_{3 \mathrm{~b}}=k_{3 \mathrm{~b}} Z_{1} \cdot \theta_{1}^{\circ}
\end{array}\right.
\end{gathered}
$$

with

$$
\begin{aligned}
& \theta_{1}=\frac{C_{A S_{1}}}{C_{S_{2} A S_{1}}+C_{A S_{1}}+C_{S_{1}}}=\frac{C_{A S_{1}}}{Z_{1}}, \\
& \theta_{1}^{*}=\frac{C_{S_{2} A S_{1}}}{C_{S_{2} A S_{1}}+C_{A S_{1}}+C_{S_{1}}}=\frac{C_{S_{2} A S_{1}}}{Z_{1}}, \\
& \theta_{2}=\frac{C_{A S_{2}}}{C_{S_{2} A S_{1}}+C_{A S_{2}}+C_{S_{2}}}=\frac{C_{A S_{2}}}{Z_{2}} .
\end{aligned}
$$

These models are compared in Fig. 4. It can be seen that they both describe very well the ethene transient (see Fig. 4a). However, model A2 fails to describe the infrared signal (Fig. 4b) predicting its immediate decrease after the stop. To describe the experimentally observed desorption of surface species, the use of finite rates of adsorption and desorption is necessary. Therefore model A1 was used to simulate the transients for the catalysts with $2.5,5.0$ and $7.5 \% \mathrm{Mg}^{2+}$.

The optimum parameter values at $200^{\circ} \mathrm{C}$ for model $\mathrm{A} 1$ are summarised in Table 1 . The values of the equilibrium constant in brackets are obtained by dividing the rate constants of adsorption by that of desorption $\left(K_{2}=k_{2} / k_{-2}\right)$.

It can be seen that:

- $k_{1}$ diminishes when the magnesium content increases. As this parameter is not sensitive, due to the almost 
Table 1

Optimum parameter values at $200^{\circ} \mathrm{C}$ as a function of the magnesium content

\begin{tabular}{|c|c|c|c|c|c|c|c|}
\hline $\begin{array}{l}\mathrm{Mg}^{2+} / \mathrm{Al}^{3+} \\
(\%)\end{array}$ & $\begin{array}{l}k_{1} \times 10^{5} \\
\left(\mathrm{~m}^{3} / \mathrm{mol} \mathrm{s}\right)\end{array}$ & $\begin{array}{l}K_{2} \\
\left(\mathrm{~m}^{3} / \mathrm{mol}\right)\end{array}$ & $\begin{array}{l}k_{2} \times 10^{5} \\
\left(\mathrm{~m}^{3} / \mathrm{mol} \mathrm{s}\right)\end{array}$ & $\begin{array}{l}k_{-2} \times 10^{5} \\
(1 / \mathrm{s})\end{array}$ & $\begin{array}{l}k_{3} \times 10^{5} \\
(\mathrm{~kg} \mathrm{~mol} \mathrm{~s})\end{array}$ & $\begin{array}{l}k_{\mathrm{D}} \times 10^{5} \\
\left(\mathrm{~m}^{3} / \mathrm{kg} \mathrm{s}\right)\end{array}$ & $\begin{array}{l}\alpha \\
\left(\mathrm{mol}^{-1}\right)\end{array}$ \\
\hline 0.05 & 2900 & 5.0 & - & - & 30.8 & 340 & 21000 \\
\hline 2.5 & 1450 & (9.7) & 970 & 100 & 8.2 & 140 & 24000 \\
\hline 5.0 & 290 & (7.1) & 378 & 53.3 & 3.8 & 88 & 21000 \\
\hline 7.5 & 290 & (5.4) & 66 & 12.1 & 2.5 & 73 & 29000 \\
\hline
\end{tabular}

complete coverage of the acid sites, the decrease is not regular;

- the estimated parameter $K_{2}$ increases with the magnesium concentration, passes through a maximum for the $2.5 \%$ catalyst and then decreases. The maximum for this parameter reflects that the observed relative rate increase after the stop is maximum on the $2.5 \%$ $\mathrm{Mg}^{2+}$-modified alumina;

- $k_{2}$ and $k_{-2}$ decrease with the magnesium concentration;

- $k_{3}$ decreases with the magnesium concentration;

- $k_{D}$ decreases with the magnesium concentration;

- $\alpha$ varies around an average value of $23,000 \pm 4000$.

As discussed for the steady-state behaviour, an increase of the magnesium concentration leads to a diminution of the acid sites strength. This explains the predicted decrease of the adsorption rate $\left(k_{1}\right)$ on the sites $S_{1}$ as well as the reduced reaction rate constants $k_{3}$ and $k_{D}$. As the acid sites strength diminishes, the bond between the oxygen of the reacting species and the catalyst surface becomes weaker. This diminishes the $\mathrm{C}-\mathrm{O}$ bond activation which results in a reduced rate of ethanol transformation. By increasing the magnesium content in the catalyst, its basicity increases, leading to a simultaneous drastic decrease of the rate constant for the desorption from the basic sites, $k_{-2}$. Since $k_{2}$ and $k_{-2}$ are related via the adsorption equilibrium constant $K_{2}$, which does not show a similar drastic variation, thus former rate constant also decreases.

Activation energies were derived from the transient experiments at 180 and $220^{\circ} \mathrm{C}$. The apparent activation energy of ethene formation (step 3) does not vary with the magnesium concentration and was found to be $105 \pm 5$ $\mathrm{kJ} / \mathrm{mol}$, whereas that of the diethylether formation decreases from $77 \pm 7 \mathrm{~kJ} / \mathrm{mol}$ on the pure alumina to $34 \pm 5 \mathrm{~kJ} / \mathrm{mol}$ on the $7.5 \% \mathrm{Mg}^{2+}$-modified $\gamma$-alumina. This confirms that, as for the stationary measurements, an increase of the magnesium content favours the intermolecular reaction.

The behaviour of the model parameter $K_{2}$ is more difficult to interpret. An increase of its value with the catalyst basicity is expected, as it represents the equilib- rium constant for the adsorption on the basic sites. The estimated maximum of $K_{2}$ reflects the observed maximum relative rate of ethene formation within the transients.

A possible explanation for the existence of a maximum would be that the surface acidity, which decreases upon the magnesium introduction, also influences the adsorption of the inhibiting species. For example, a stabilisation of the inhibiting species by interaction of its oxygen atom with a neighbouring acid hydroxyl group can be imagined. As the magnesium concentration is increased, this stabilising effect would hence diminish. The $2.5 \%$ catalyst would present an optimum between the intrinsic increase of the basic site strength and the diminution of the neighbouring effect of the acid sites, explaining thus the existence of a maximum.

\section{Conclusions}

Surface basicity of catalyst can be increased by incorporating $\mathrm{Mg}^{2+}$ in the alumina lattice. Under steady-state conditions the ethene yield decreases with increasing $\mathrm{Mg}^{2+}$ content, whereas the relative maximum rate of ethene formation after a stop of ethanol feed increases and passes through a maximum for catalysts with $2.5 \%$ $\mathrm{Mg}^{2+}$.

The results obtained under steady-state can be explained by the strength of adsorption of the ethanol on the acid sites. With decreasing acidity the $\mathrm{C}_{2} \mathrm{H}_{5}-\mathrm{O}$ bond is strengthen and leads to a preferred intermolecular reaction thus decreasing the rate of ethene formation.

The transient experiments are more sensitive to the catalyst acid/base properties than the steady-state measurements. This higher sensitivity is due to the complexity of the transient behaviour, which is directed by species adsorbed on acid sites and species adsorbed on basic sites. Therefore the transient behaviour is not only affected by the surface acidity but also by the sorption kinetics on the basic sites.

Finally, a modified two sites model is proposed to describe the observed transients. 


\section{Acknowledgements}

The authors gratefully acknowledge the funding from the Swiss National Science Foundation and the Max Buchner Forschungsstiftung, Frankfurt, Germany.

\section{Notation}

a cell parameter, $\mathrm{nm}$

A ethanol

C gas-phase concentration, $\mathrm{m}^{3} / \mathrm{mol}$

D diethylether

E ethene

$g$ exponential activity distribution parameter, dimensionless

$h_{\text {spectator }}$ infrared absorbance of the spectator species, dimensionless

$k \quad$ rate constant, various units

$K \quad$ equilibrium constant, $\mathrm{m}^{3} / \mathrm{mol}$

NTP normal conditions of temperature and pressure $\left(0^{\circ} \mathrm{C}, 1.013 \times 10^{5} \mathrm{~Pa}\right)$

$Q \quad$ total flow rate, $\mathrm{ml}(\mathrm{NTP}) / \mathrm{min}$

$r \quad$ rate constant, $\mathrm{mol} / \mathrm{kg}_{\text {cat }} \mathrm{S}$

$\mathrm{S} \quad$ catalytic site

T temperature, ${ }^{\circ} \mathrm{C}$

W water

$\mathrm{Z} \quad$ surface sites concentration, $\mathrm{mol} / \mathrm{kg}_{\text {cat }}$

\section{Greek letters}

$\alpha$ proportionality coefficient of the infrared signal, $\mathrm{mol}^{-1}$

exponential activity distribution parameter, $\mathrm{kJ} / \mathrm{mol}$

ratio between the concentration of sites 2 and sites 1 , dimensionless surface coverage, dimensionless

\section{Subscripts}

$\begin{array}{ll}0 & \text { reactor inlet } \\ 1 & \text { site type } \\ 2 & \text { site type } \\ A & \text { ethanol } \\ \text { cat } & \text { catalyst } \\ \text { cell } & \text { infrared cell } \\ D & \text { diethylether } \\ R & \text { reactor }\end{array}$

\section{References}

Golay, S. (1998) Ph. D. thesis, Federal Institute of Technology, Lausanne, Switzerland.

Golay, S., Doepper, R., \& Renken, A. (1998). In situ characterisation of the surface intermediates for the ethanol dehydration reaction over $\gamma$-alumina under dynamic conditions. Appl Catal. A: General, in press.

Golay, S., Wolfrath, O., Doepper, R., \& Renken, A. (1997). Model discrimination for reactions with stop-effect. Stud. Surf. Sci. Catal., 109, 295-304.

Kiwi-Minsker, L., Porchet, S., Doepper, R., \& Renken, A. (1997). Catalyst acid/base properties regulation to control the selectivity in gas-phase methylation of catechol. Stud. Surf. Sci. Catal., 108, 149-256.

Kiwi-Minsker, L., Porchet, S., Moeckli, P., Doepper, R., \& Renken, A. (1996). Selective methylation of catechol: catalyst development and characterisation. Stud. Surf. Sci. Catal., 101, 171-180.

Koubek, J., Pasek, J., \& Ruzicka, V. (1980a). New horizons in catalysis, (pp. 853-862). Amsterdam: Elsevier.

Koubek, J., Pasek, J., \& Ruzicka, V. (1980b). Catalyst deactivation, (pp. 251-260). Amsterdam: Elsevier.

Moravek, V., \& Kraus, M. (1984). Transient behavior of the system ethanol-diethyl ether-water-alumina. J. Catal., 87, 452-460.

Porchet, S. (1996) Ph.D. thesis, Federal Institute of Technology, Lausanne, Switzerland.

Simusolv (1990). Modeling and simulation software, reference Guide. Midland, MI: Dow Chemical Company. 